\title{
Relação entre autoconceito de crianças e estilos de liderança de professores
}

\author{
Jéssica Michelis Lemos \\ Universidade Estadual do Centro-Oeste - Irati - PR - Brasil \\ Ana Priscila Batista \\ Universidade Estadual do Centro-Oeste - Irati - PR - Brasil
}

\begin{abstract}
Resumo
A interação professor-aluno é essencial para o desenvolvimento das crianças. Essa interação influencia diversos aspectos do comportamento infantil, dentre estes, o autoconceito. Este trabalho teve por objetivo verificar a relação entre o autoconceito em crianças e os estilos de liderança de professores. Participaram dessa pesquisa 124 alunos com idade média de 9,5 (DP=1,29), de $4^{\circ}$ e $5^{\circ}$ anos do Ensino Fundamental, de escolas públicas. Para a coleta de dados foram utilizados dois instrumentos, a Escala de Autoconceito Infanto-Juvenil (EAC-IJ) e o Inventário de Estilos de Liderança de Professores (IELP). Os resultados mostraram três correlações, uma positiva e duas negativas, além da classificação quanto aos estilos de liderança de professores e a classificação dos autoconceitos das crianças. O estudo aponta para a necessidade de se considerar as relações sociais estabelecidas na escola e promove uma reflexão sobre a importância dessas relações para o desenvolvimento infantil.
\end{abstract}

Palavras-chave: Autoconceito;Interação professor-aluno;liderança.

\section{The relationship between self-concept of children and teacher leadership styles}

\begin{abstract}
The teacher-student interaction is essential for the development of children. This interaction influences several aspects of the child's behavior, among them, the self-concept. This study aimed to verify the relationship between self-concept in children and teacher leadership styles. A total of 124 students with a mean age of 9.5 (SD = 1.29), 4th and 5th years of Elementary School, from public schools participated in this study. Two instruments were used to collect data, the Child-Youth Self-Concept Scale (EAC-IJ) and the Teacher Leadership Styles Inventory (IELP). The results showed three correlations, one positive and two negative, as well as the classification of teacher leadership styles and the classification of children's self-concepts. The study points to the need to consider the social relations established in the school and promote a reflection on the importance of these relationships for child development.
\end{abstract}

Keywords: Self-concept; teacher-student interaction;leadership.

\section{Relación entre auto concepto de niños y estilos de liderazgo de profesores}

\section{Resumen}

La interacción profesor-alumno es esencial para el desarrollo de los niños. Esa interacción influencia diversos aspectos del comportamiento infantil, entre éstos, el auto concepto. Este estudio tuvo por objetivo verificar la relación entre el auto concepto en niños y los estilos de liderazgo de profesores. Participaron de esa investigación 124 alumnos con un promedio de edad de 9,5 (DP=1,29), de $4^{\circ}$ y $5^{\circ}$ cursos de la Enseñanza Primaria, de escuelas públicas. Para la recolecta de datos se utilizó dos instrumentos, la Escala de Auto concepto Infanto-Juvenil (EAC-IJ) y el Inventario de Estilos de Liderazgo de Profesores (IELP). Los resultados mostraron tres correlaciones, una positiva y dos negativas, además de la clasificación cuanto a los estilos de liderazgo de profesores y la clasificación de los auto conceptos de los niños. El estudio apunta para la necesidad de considerarse las relaciones sociales establecidas en la escuela y promueve una reflexión sobre la importancia de esas relaciones para el desarrollo infantil.

Palabras clave: Auto concepto; Interacción profesor-alumno; liderazgo. 


\section{Introdução}

As várias relações estabelecidas na infância são responsáveis por influenciar a aprendizagemde comportamentos, que poderão repercutir por toda a vida. Perceber a influência dos grupos sociais mais significativos é importante, porque contribuem para a construção do autoconceito dos indivíduos (Antunes \& Fontaine, 2005).

Dessa forma, é importante observar e analisar a interação estabelecida entre professor e alunos, pois esse profissional passa boa parte do tempo com as crianças e, segundo Hamre e Pianta (2006), as crianças dependem extensivamente dos professores nos anos iniciais do Ensino Fundamental, pois são eles que estruturam suas experiências diárias, facilitam as relações entre pares e regulam emoções e comportamentos. Assim, observa-se que professores podem ter uma influência difusa sobre vários aspectos do desenvolvimento infantil, dentre eles, o autoconceito. O autoconceito em crianças atualmente é uma área de grande investigação na psicologia e é brevemente definido por Serra (1988) como a percepção que o indivíduo tem de si próprio. É importante ressaltar que essa área de estudo é recente, de modo que não existem pesquisas que relacionem essas variáveis. Nesse sentido, fica evidente a importância deste estudo, por se tratar de uma área recorrente na vida de todos.

\section{Autoconceito}

O estudo das representações acerca de si próprio tem se mostrado uma área de grande investigação na psicologia. O primeiro estudioso a analisar metodicamente a noção de autoconceito foi William James. James, em 1890 (conforme citado por Costa, 2002) considerou a consciência do indivíduo sobre o que se está pensando ou sobre o que se está percebendo em relação aos aspectos e processos físicos, bem como as ideias que as pessoas têm sobre como elas são e como elas gostariam de ser. Este fenômeno, segundo Costa (2002), é caracterizado na psicologia como pensamento autorreferente, também denominado como autoimagem, identidade e autoconceito.

De forma geral, o autoconceito pode ser definido como sendo o conhecimento que o indivíduo tem de si,as características ou atributos que são utilizados para a autodescrição (Palácios \&Hidalgo,1995; Sisto \& Matinelli, 2004). Shavelson, Hubner, e Stanton (1976) definem o autoconceitocomo a percepção que a pessoa tem de si, formada a partir da experiência com o ambiente, sendo influenciada pelos reforços ambientais e de pessoas significativas. Nesse sentido, o autoconceito é fortemente influenciado pelas relações sociais que se travam entre o indivíduo e o meio no decorrer de sua existência.

Segundo Rocha, Ingberman, e Breus (2011) o autoconceito, de acordo com a perspectiva da análise do comportamento, é definido como comportamento verbal autodescritivo que é aprendido, relacionando-se às maneiras pelas quais o indivíduo se comporta e podendo ser visto, então, como uma forma de autoconhecimento. É coerente afirmar que a comunidade verbal é quem promove o desenvolvimento do autoconceito, ou seja, a maneira como os outros reagem ao comportamento influencia as características do autoconceito. Dessa forma, não se pode dizer que o autoconceito é a causa do comportamento, mas é um comportamento verbal que está funcionalmente relacionado com outros comportamentos. Na mesma direção, Carneiro, Martinelli, e Sisto (2003) afirmam que a formação do autoconceito é um processo lento, que se desenvolve ao longo do tempo nas experiências pessoais e nas relações com os outros.

Assim, se por um lado, a percepção que a pessoa tem de si mesma influencia o modo como age, por outro, são seus atos que influenciam a maneira como ela mesma e o mundo a percebem (Rocha, Ingberman, \& Breus, 2011). Dessa maneira, o autoconceito, segundo esta abordagem, pode ser visto como uma forma de autoconhecimento.

Relacionado ao autoconceito, no contexto escolar, está o conceito de autoeficácia. Postulado por Bandura (1986, conforme citado por Souza \& Brito, 2008), a autoeficácia pode ser definida como a crença na própria capacidade de organizar e executar ações para determinadas realizações, ou seja, compreende um julgamento pessoal de capacidade para determinado domínio.

Os dois constructos, autoconceito e a autoeficácia, apresentam algumas semelhanças, de modo que se relacionam a comportamentos autorreferentes, exercendo controle sobre eventos que podem afetar a vida. Entretanto, existem divergências, as quais são apontadas por Pajares (1996), de modo que a autoeficácia se caracteriza como uma avaliação de competência para a realização de atividades em contextos específicos, já o autoconceito aborda crenças de autovalorização, que estão relacionadas às capacidades percebidas de cada sujeito.

Segundo Pajares e Schunk (2001), há evidência de que as crenças de autoeficácia e o autoconceito são relacionadas e influenciam o rendimento acadêmico, de modo que alunos confiantes em suas capacidades atingem bons resultados acadêmicos, ou seja, a confiança nas capacidades acadêmicas é um componente crítico do sucesso escolar.

\section{Interação professor-aluno}

Durante os anos iniciais da escolarização, as crianças permanecem a maior parte de seu tempo em casa e na escola (Davis-Kean\& Eccles, 2005). Dessa maneira, a escola é um dos principais meios sociais no qual a criança está inserida. Assim, deve-se compreendê-la, visando sistematizar os aspectos que permeiam as relações que ali se constroem,dentre elas, as interações constituídas entre professor e aluno. Essa relação é fundamental para o desenvolvimento integral das crianças. Segundo Barbosa, Campos, e Valentim (2011), a partir da relação com os professores, a criança adquire conhecimentos para todo o curso de vida e tem suas capacidades psicossociais promovidas. 
Ribeiro (2010) assinala que, na atualidade, o papel do professor diz respeito à cumplicidade na construção de novos saberes e atitudes. De forma geral, é esperado que as interações estabelecidas entre professor e aluno, assim como as demais relações presentes no ambiente escolar, possam propiciar o aumento do desenvolvimento cognitivo da criança,bem como promover o seu desenvolvimento geral. Esse mesmo autor aponta que o papel do professor vem se tornando cada vez mais complexo, deixando de ser apenas aquele que transmite informações, sendo considerado parceiro na construção dos conhecimentos, o que implica novos saberes e atitudes que possibilitam aos estudantes integrar, no processo de aprendizagem das disciplinas, os aspectos cognitivo, afetivo e a formação de atitudes.

Segundo Batista (2013), o estilo de liderança de professores "refere-se ao comportamento do professor direcionado aos alunos, criando diferentes climas emocionais em salas de aulas em função das práticas que adotam, o que repercute de diversas formas sobre o comportamento dos alunos" (p.32).

Conforme se configura o estilo de liderança do professor, este pode se apresentar como fator de proteção ou até mesmo de risco para o desenvolvimento da criança. Assim, compreender as interações que ocorrem no ambiente escolar pode auxiliar os profissionais que atuam na Educação a terem uma visão mais ampla dos estilos de liderança e suas repercussões, pensar em propostas de prevenção e intervenção eficazes, bem como avaliar a formação, inicial ou continuada, de professores (Batista, 2013).

De acordo com Batista (2013) e Batista e Weber (2015), os estilos de liderança surgem do cruzamento de duas dimensões, que são a responsividade e a exigência, que podem somar-se à dimensão controle coercitivo ${ }^{1}$. A dimensão responsividade refere-se à qualidade na comunicação, envolvimento, reciprocidade e afetividade do professor em relação aos alunos. A dimensão exigência pode ser considerada em relação às atitudes dos professores de supervisionar, monitorar e controlar o comportamento dos alunos de forma a impor e fazer cumprir limites e regras na sala de aula e em todo o contexto escolar. A dimensão controle coercitivo refere-se ao comportamento do professor de impor uma situação aversiva/negativa em sala de aula e na escola, utilizar ameaças e punir de forma inadequada o comportamento dos alunos.

O estilo autoritativo é aquele que possui a responsividade e a exigência em equilíbrio. Nesse estilo o professor apresenta claramente o nível de exigência da escola e da sala de aula pelo estabelecimento de regras, limites e monitoria do comportamento, ao mesmo tempo em que demonstra afetividade, envolvimento e qualidade de comunicação nas relações. No estilo autoritário predominam a alta exigência e a baixa responsividade. São professores

1 Controle Coercitivo: Mais pertinente para descrever um controle negativo que ocorre de forma intensa, opressiva, não justificável, atendendo muito mais ao professor do que ao aluno. Esse termo substitui o "controle aversivo" utilizado por Batista 2013 (Batista \& Weber, 2015). que valorizam a autoridade, a ordem e a estrutura tradicional sem atentar às demandas dos alunos. O estilo permissivo é aquele no qual os professores são muito responsivos e não exigentes. Não estabelecem regras e limites apropriados ou até estabelecem, mas não cumprem com as consequências estabelecidas quando os alunos não as seguem, não monitoram os comportamentos, realizando os desejos da criança. O estilo negligente é definido como professores não responsivos nem exigentes. Ao mesmo tempo em que não estabelecem regras e limites, não monitoram o comportamento dos alunos, não se envolvem e não são afetivos com as crianças (Batista, 2013). A esses quatro estilos pode somar-se o controle coercitivo que, para Sidman (1989/1995), entra em cena quando os comportamentos são controlados por reforçamento negativo ou punição.

A partir do exposto, fica clara a importância dos estilos de liderança que os professores apresentam, pois acredita-se que estas diferentes formas de relações podem influenciar diversos aspectos do comportamento infantil, dentre eles, o autoconceito.

Segundo Mattos, Pérez, e Castro (2013), a relação entre professor e aluno é atravessada pela troca de conhecimento, e também pelo afeto e pelo cuidado. Além da transmissão de conteúdos, são estabelecidas relações emocionais significativas entre as partes. Sendo assim, é na escola que a criança busca o atendimento de algumas de suas necessidades. Por isso é importante que, na relação entre professor e aluno, sejam levados em consideração tanto os aspectos cognitivos quanto os aspectos afetivos desta relação e, nesse sentido, os professores constituem um grupo de adultos cujo apoio é relevante para a formação do autoconceito.

\section{Interação professor-aluno e autoconceito em crianças}

A relação professor-aluno é necessária para o engajamento das crianças na aprendizagem e também, a base para o desenvolvimento de uma ideia sobre si mesmo e sobre o mundo social, além de contribuir para a aquisição de comportamentos e capacidades, essenciais no ambiente escolar (Barbosa, Campos, \& Valentim, 2011).

Concomitante à elaboração dos aspectos psicológicos do seu autoconceito, a criança vai descobrindo e elaborando a dimensão social do seu eu (Cia \& Barham, 2008). É ao longo das etapas de escolarização que a criança vai se tornando consciente do quanto ela é capaz de realizar e aprender. As pessoas que afetam o autoconceito que a criança desenvolve são, geralmente, os adultos importantes em sua vida, como os pais e professores que, na maioria das vezes, exercem algum controle sobre a criança e cujas opiniões têm influência sobre ela (Carneiro, Martinelli, \& Sisto, 2003).

O autoconceito tem sido destacado tendo em vista a importância dada a esse constructo na dinâmica das relações que ocorrem no ambiente escolar. Segundo Júnior e Cunha (2007), toda criança chega à escola com experi- 
ências anteriores que já Ihe deram uma visão de si mesma. Assim, a escola poderá tanto reforçar essa imagem como propiciar experiências que a modifiquem, uma vez que, junto com a figura dos pais, os professores agora passam a ser também um referencial para o aluno.

De acordo com o que foi exposto, fica evidente a importância da forma como o professor interage com seus alunos para o desenvolvimento integral dos mesmos e, também para o autoconceito, por esse se tratar de um adulto que está presente durante grande parte do tempo com crianças, estruturando suas atividades diárias. Considerando esse fato, o trabalho aqui apresentado é de grande relevância científica e social, de modo que os temas abordados são de recorrência na vida de todos. Apesar da importância dos temas, não há pesquisas nessa área, ou seja, não há pesquisas que relacionem essas duas variáveis, autoconceito e estilos de liderança de professores. Até devido ao fato de que o construto "estilos de liderança de professores" e as dimensões de responsividade, exigência e controle coercitivo, analisadas, são recentes na literatura da área (Batista, 2013; Batista \& Weber, 2012, 2015). Diante disso, observa-se a importância de se trabalhar com essa relação, pois o autoconceito é construído ao longo da vida, e um dos ambientes mais frequentados durante grande período da infância, é o escolar.

Sendo assim, para a realização da presente pesquisa, optou-se por escolher alunos do $4^{\circ}$ e $5^{\circ}$ anos do Ensino Fundamental, por estes possuírem um(a) professor(a) regente durante a maior parte do tempo, ficando mais evidente a relação entre eles. Optou-se também que a coleta de dados fosse realizada no semestre final, pois assim os participantes já haviam passado por pelo menos um semestre de convivência.

O presente trabalho,então, teve como objetivo verificar a relação entre o autoconceito em crianças e os estilos de liderança de professores, além de também apresentar dados sobre o autoconceito das crianças e os estilos de liderança de professores na amostra estudada.

\section{Método}

\section{Participantes}

Participaram deste estudo 124 alunos, com idade média de 9,5 anos, desvio padrão (DP) de 1,29. Foram quatro turmas do $4^{\circ}$ ano e quatro turmas do $5^{\circ}$ ano do Ensino Fundamental de três escolas públicas do interior do Para- ná, selecionados por conveniência. Os dados referentes à frequência e porcentagem quanto ao gênero, ano escolar e idade, encontram-se na Tabela 1.

\section{Instrumentos}

Para a realização do estudo foram utilizados dois instrumentos, um que mede o autoconceito em crianças e outro que mede os estilos de liderança de professores, os quais estão descritos a seguir:

Escala de Autoconceito Infanto-Juvenil (EAC-IJ): Criada por Sisto e Martinelli (2004) e aprovada pelo Conselho Federal de Psicologia (CFP), tem por objetivo avaliar, com maior precisão, os diferentes níveis de autoconceito: autoconceito pessoal, autoconceito social, autoconceito familiar e autoconceito escolar. Analisando a interação entre a pessoa e o seu meio ambiente, durante seu processo de construção social e ciclo de vida, acompanhado de uma avaliação de suas capacidades, realizações, experiências e representações em diferentes contextos sociais com os quais interage. Os escores referentes a este instrumento foram utilizados para a análise na forma de dado bruto, ou seja, obtiveram-se os escores totais de autoconceito pessoal, escolar, familiar, social e geral, somando-se os escores de acordo com a correção do instrumento.

Inventário de Estilos de Liderança de Professores (IELP): Desenvolvido por Batista (2013) e publicado por Batista e Weber (2015) tem porfinalidade identificar os estilos de liderança de professores, o qual se constitui por 56 itens como, por exemplo, "Minha professora é alegre", que devem ser respondidos com uma das opções "nunca ou quase nunca", "às vezes" ou "sempre ou quase sempre", configurando-se em uma escala Likert de três pontos. O instrumento de auto relato se subdivide em 21 itens referentes à escala sobre responsividade, descrita como qualidade na comunicação, cordialidade, envolvimento, apoio, cuidado, reciprocidade e afetividade do professor em relação aos alunos; 16 itens na escala de exigência, descrita como atitudes dos professores de estabelecer expectativas de desempenho, cobrar, monitorar, supervisionar e controlar o comportamento dos alunos de forma a impor limites e regras na sala de aula e em todo o ambiente escolar e 19 itens na escala de controle coercitivo, que se refere ao comportamento do professor de impor uma situação aversiva/negativa em sala de aula e na escola, utilizar ameaças e punir de forma inadequada o comportamento dos alunos. De acordo com esses fatores, os estilos de

Tabela 1. Frequência e porcentagem quanto ao gênero, ano escolar e idade da amostra de participantes.

\begin{tabular}{lccccccccc}
\hline & \multicolumn{3}{c}{ Gênero } & \multicolumn{2}{c}{ Ano Escolar } & \multicolumn{3}{c}{ Idade } \\
\cline { 2 - 9 } & $\mathbf{F}$ & $\mathbf{M}$ & $\mathbf{4}^{\circ}$ & $\mathbf{5}^{\circ}$ & $\mathbf{8}$ & $\mathbf{9}$ & $\mathbf{1 0}$ & $\mathbf{1 1}$ \\
\cline { 2 - 9 } Frequência & 56 & 68 & 41 & 83 & 7 & 51 & 60 & 6 \\
Porcentagem & 45,2 & 54,8 & 33,1 & 66,9 & 5,6 & 41,1 & 48,4 & 4,8 \\
\hline
\end{tabular}


liderança de professores puderam ser classificados como: autoritário, autoritativo, negligente ou permissivo, somados em alguma medida ao controle coercitivo.

\section{Procedimento}

Inicialmente foi feito contato e apresentado o projeto para a direção de Escolas Públicas do primeiro ciclo do Ensino Fundamental, no momento em que foi entregue um Termo de Consentimento Livre e Esclarecido (TCLE) para o/a responsável pela direção das escolas e professoras das turmas de $4^{\circ}$ e $5^{\circ}$ anos, solicitando a permissão para a pesquisa.

As professoras encaminharam aos pais dos alunos, ou responsáveis por eles, um TCLE para que lessem e assinassem, caso concordassem com a participação de seus filhos no estudo. Somente aqueles alunos cujos pais assinaram o TCLE e devolveram à pesquisadora responderam ao instrumento, sendo essa participação voluntária. Os alunos cujos pais concordaram com a pesquisa também assinaram um termo de assentimento, concordando com a participação no estudo.

A aplicação dos instrumentos foi feita de forma coletiva em uma sala de aula da própria escola, durante o horário da aula. No início de cada aplicação, as crianças foram informadas sobre a pesquisa, a garantia da confidencialidade dos dados, o caráter voluntário da participação e a necessidade de não conversarem entre si durante o preenchimento do instrumento. Uma pessoa treinada auxiliou nesse processo, monitorando o preenchimento do instrumento pelos alunos, passando entre as carteiras, e ficando disponível para tirar dúvidas.

Primeiramente foi aplicado o Inventário de Estilos de Liderança de Professores (IELP) e em seguida a Escala de Autoconceito Infanto-Juvenil (EAC-IJ). O tempo necessário para a aplicação dos instrumentos foi de 50 minutos.A pesquisa foi autorizada pelo Comitê de Ética em Pesquisa em Seres Humanos, conforme parecer $n^{\circ} 673.553$.

\section{Análise dos Dados}

A partir dos dados coletados foram realizadas análises utilizando o Software Statistical Package for the Social Sciences (SPSS), versão para Windows. Com o instrumento EAC-IJ foram obtidos os escores brutos de cada participante sobre o autoconceito pessoal, autoconceito escolar, autoconceito familiar, autoconceito social, e autoconceito geral, o percentil correspondente e a classificação recebida. Com o instrumento IELP foram obtidos os escores de cada participante referentes a cada escala (responsividade, exigência e controle coercitivo), o percentil correspondente, a classificação recebida e o estilo de liderança do professor, a partir da perspectiva do aluno.

Com esses dados, foram realizadas análises correlacionais buscando identificar relações entre os diferentes autoconceitos e estilos de liderança de professores. Segundo Cozby (2009), quanto mais próximo estiver de $+1,0$ ou $-1,0$, mais forte é a relação. Um valor de 1,0 indica uma correlação que pode ser considerada perfeita enquanto um valor zero indica uma completa ausência de relação. Os sinais mais e menos indicam se há uma relação linear positiva ou negativa entre as variáveis, respectivamente.

\section{Resultados e Discussão}

Inicialmente é apresentado o estudo sobre a classificaçãodos autoconceitos, a qual foi feita de acordo com o percentil, sendo dividido em três quartis, 25, 50 e 75, sendo 50 corresponde à mediana. Os dados da amostra referentes à porcentagem quanto à classificação dos autoconceitos encontram-se na Figura 1.

Essa análise demonstrou que a maior parte dos alunos $(55,6 \%)$ possui um bom autoconceito pessoal, percebendo-se de bem com a vida e levando os problemas

Maior que a mediana Mediana Menor que a mediana

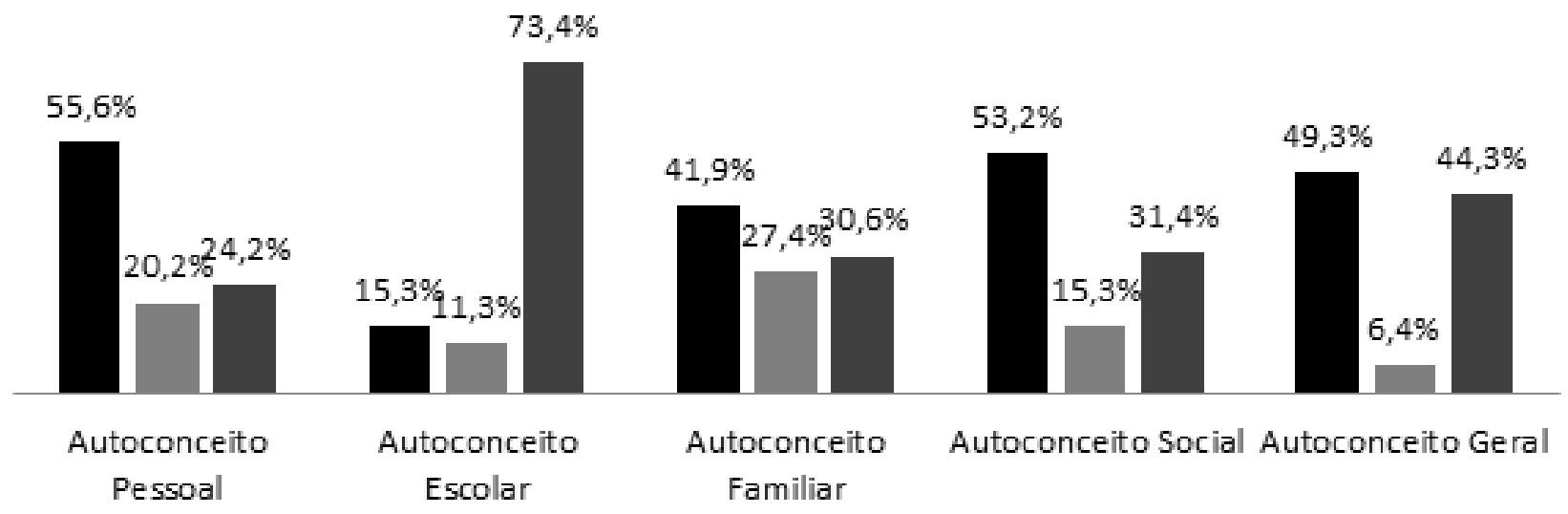

Classificação dos Autoconceitos

Figura 1. Porcentagem quanto à classificação dos autoconceitos da amostra de participantes. 
sem dificuldades. Os autoconceitos social, geral e familiar também apresentaram porcentagens altas, 53,2\%, 49,3\% e $41,9 \%$ respectivamente, demonstrando que a maioria dos participantes possui uma boa visão sobre si mesmose boas relações tanto no contexto familiar quanto no contexto externo.

Destaca-se como dado significativo que a maioria dos alunos $(73,4 \%)$, apresentou um autoconceito escolar abaixo da mediana, avaliando-se como não muito esperta para os estudos e com dificuldades de liderança. Ressalta-se que os itens da escala de autoconceito escolar estão pautados no relacionamento com os pares e como o aluno se vê no ambiente da sala de aula, não estando relacionado ao rendimento acadêmico em si, como por exemplo, o item "Meus colegas concordam com tudo o que falo" ou "Considero-me o mais esperto da classe".

A análise dos estilos de liderança de professores permitiu uma categorização dos estilos, verificados de acordo com as práticas utilizadas em sala de aula e a frequência destas. É importante ressaltar que tais classificações se originaram da correção do Inventário de Estilos de Liderança de Professores (Batista \& Weber, 2015), de acordo com as respostas dadas pelos alunos que compuseram a amostra. Os dados referentes à frequência dos Estilos de Liderança de Professores encontram-se na Figura 2.

Pode-se perceber que o estilo de liderança mais frequente na amostra foi o estilo autoritativo(48,3\%) e o menos frequente foi o estilo autoritário (4,0\%). Um fator que chama a atenção é que os estilos permissivo e negligente somam $47,6 \%$, sendo estilos que envolvem pouca, ou nenhuma exigência. A exigência refere-se às atitudes dos professores de controlar o comportamento dos alunos, estabelecendo limites e regras, sendo um fator essencial, pois dá parâmetros e direção para as crianças. A falta de exigência pode repercutir de maneira negativa no desenvolvimento da criança, pois em todos os lugares da sociedade há imposição de regras a serem seguidas. Dessa maneira, a criançapode não aprender que é importante respeitar as regras e, sua socialização, ou seja, a convivência em sociedade, incluindo a escola, pode se tornar mais difícil.

As crianças que não convivem com os limites, tendem a acreditar que não precisam dar nada em troca para as pessoas gostarem dela, nesse sentido, passam a serem excluídas, podendo se tornar antissociais e sem tolerância a frustrações. Para explicar tal fato, recorre-se ao modelo de estilos parentais, pois os aprendizados têm início com a família, podendo refletir em outros contextos (Weber, Prado, Viezzer, \& Brandenburg, 2004). Segundo Gomide (2006), os estilos parentais são o conjunto de práticas educativas utilizadas pelos cuidadores com o objetivo de educar, socializar e controlar o comportamento de seus filhos, dessa maneira tais estilos podem ser positivos ou negativos, o que evidentemente contribui para os comportamentos das crianças em vários contextos e situações. O modelo teórico dos estilos parentais, baseado nas dimensões de responsividade e exigência (Maccoby \& Martin, 1983) é uma das bases para a formulação da análise dos estilos de liderança de professores, assim, tendo relação entre essas práticas.

Ainda de acordo com a análise do escore bruto obtido em cada escala do IELP (Batista \& Weber, 2015), pode-se observar o percentil correspondente e a classificação obtida, sendo que a interpretação final do instrumento identificou os Estilos de Liderança de Professores a partir do cruzamento das diferentes classificações (alto, tendência a alto, tendência a baixo e baixo).

De acordo com a análise realizada, na escala Controle Coercitivo, os escores brutos de todos os participantes corresponderam ao percentil referente à classificação tipo

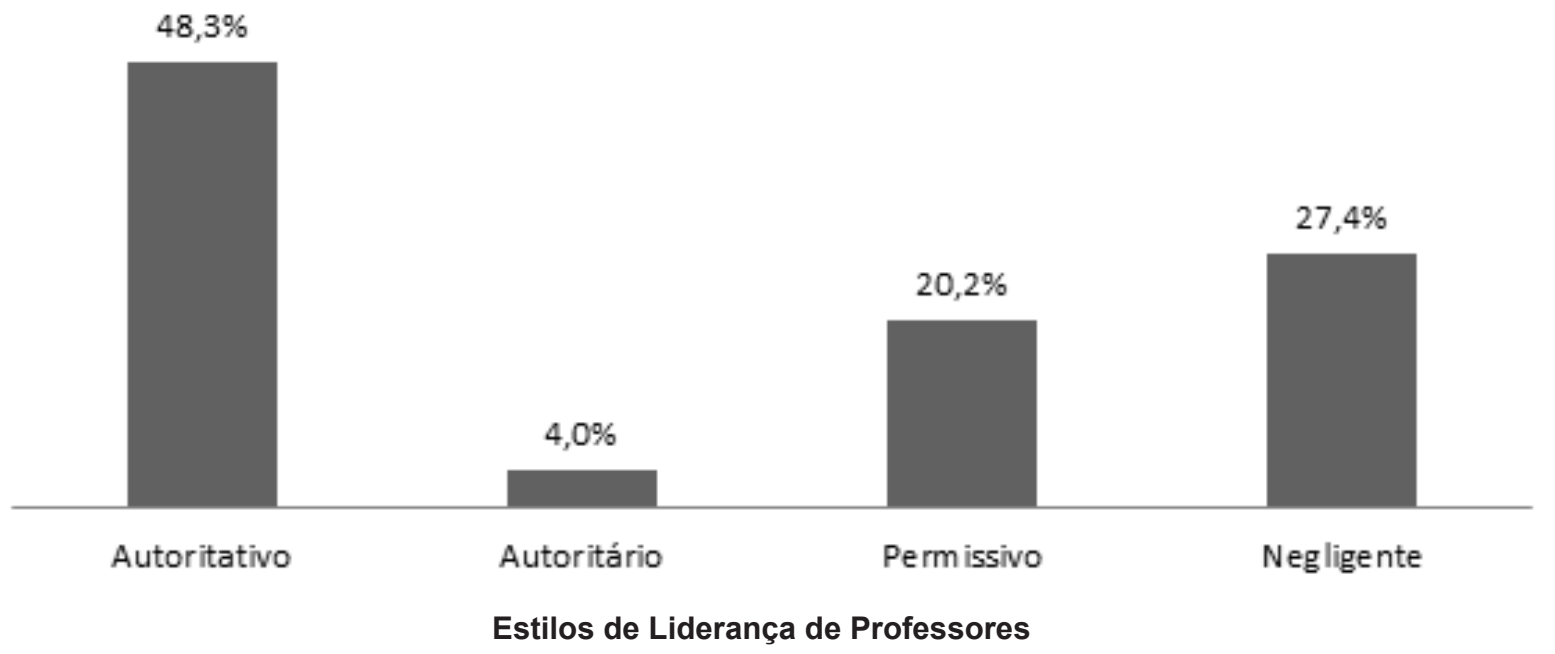

Figura 2. Frequência dos Estilos de Liderança de Professores de acordo com a amostra de participantes. 
2, caracterizado como um Controle Coercitivo tendência a baixo. Assim, todos os estilos de liderança obtidos a partir do cruzamento das escalas responsividade e exigência somam-se ao Controle Coercitivo tipo 2.

Os dados referentes à porcentagem quanto à classificação dos Estilos de Liderança a partir do cruzamento das escalas de responsividade e exigência de acordo com os tipos encontram-se na Figura 3.

Todos os estilos de liderança são compostos por quatro tipos. Eles são obtidos a partir do cruzamento das diferentes classificações obtidas nas escalas responsividade $(r)$ e exigência (e). Essas classificações são: baixo (B), tendência a baixo (TB), tendência a alto (TA) e alto (A). Assim, o estilo autoritativo tipo 1 se configura como: rAeA; o tipo 2, rAeTA; o tipo 3, rTAeA e o tipo 4, rTAeTA. Os estilos que se caracterizam como autoritário são do tipo $1, \mathrm{rBeA}$; do tipo 2, rBeTA; do tipo 3, rTBeA e do tipo 4, rTBeTA. Já no estilo permissivo encontra-se, tipo 1, rAeB; tipo 2, rAeTB; tipo 3, rTAeB e tipo 4, rTAeTB. Por fim, o estilo negligente se caracteriza de acordo com o tipo 1, rBeB; tipo 2, rBeTB; tipo 3, rTBeB e tipo 4, rTBeTB.

Essa análise mostrou que o estilo de liderança mais frequente, de acordo com a amostra de participantes, é o estilo autoritativo tipo $1(30,6 \%)$, sendo caracterizado com responsividade alta e exigência alta. Em segundo lugar encontram-se os estilos permissivo tipo 4 (12,1\%) caracterizado por responsividade tendência a alta e exigência tendência a baixa e negligente tipo $4(12,1 \%)$ definido por responsividade tendência a baixa e exigência tendência a baixa. Os estilos com menor frequência foram os autoritários tipo $2(0,0 \%)$ e tipo $3(0,0 \%)$, sendo caracterizados com responsividade baixa e exigência tendência a alta e responsividade tendência a baixa e exigência alta, respectivamente. De acordo com essa análise pode-se apontar a importância da responsividade e da exigência para o desenvolvimento das crianças, de modo que elas precisam de regras para conviver bem em sociedade, mas também precisam de apoio e afetividade para um bom desenvolvimento (Batista, 2013; Batista \& Weber, 2012). Afirmando isso, o estilo mais frequente foi o autoritativo, que combina de forma equilibrada boa comunicação, apoio, afetividade e o monitoramento do comportamento, tornando dessa forma a aprendizagem mais prazerosa e efetiva.

Ao buscar identificar relações entre os diferentes autoconceitos e as escalas do IELP, utilizando o coeficiente de Correlação de Pearson, observou-se algumas correlações que podem ser visualizadas na Tabela 2.

Houve correlação positiva estatisticamente significativa $(p<0,05)$ entre a responsividade e o autoconceito familiar ( $r=0,24, r^{2}=5,8 \%$ ), de maneira que, quanto maior a responsividade do professor, maior o autoconceito familiar. Entretanto, questiona-se qual a relação entre o autoconceito familiar e a interação professor-aluno. Para tentar responder a isso, foi realizada uma análise dos itens dessas escalas contidas nos dois instrumentos. Observou-se que a escala de responsividade é composta por itens relacionados à qualidade na comunicação, envolvimento e afetividade, fatores que também ficam evidentes nos itens relacionados ao auto-

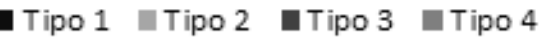

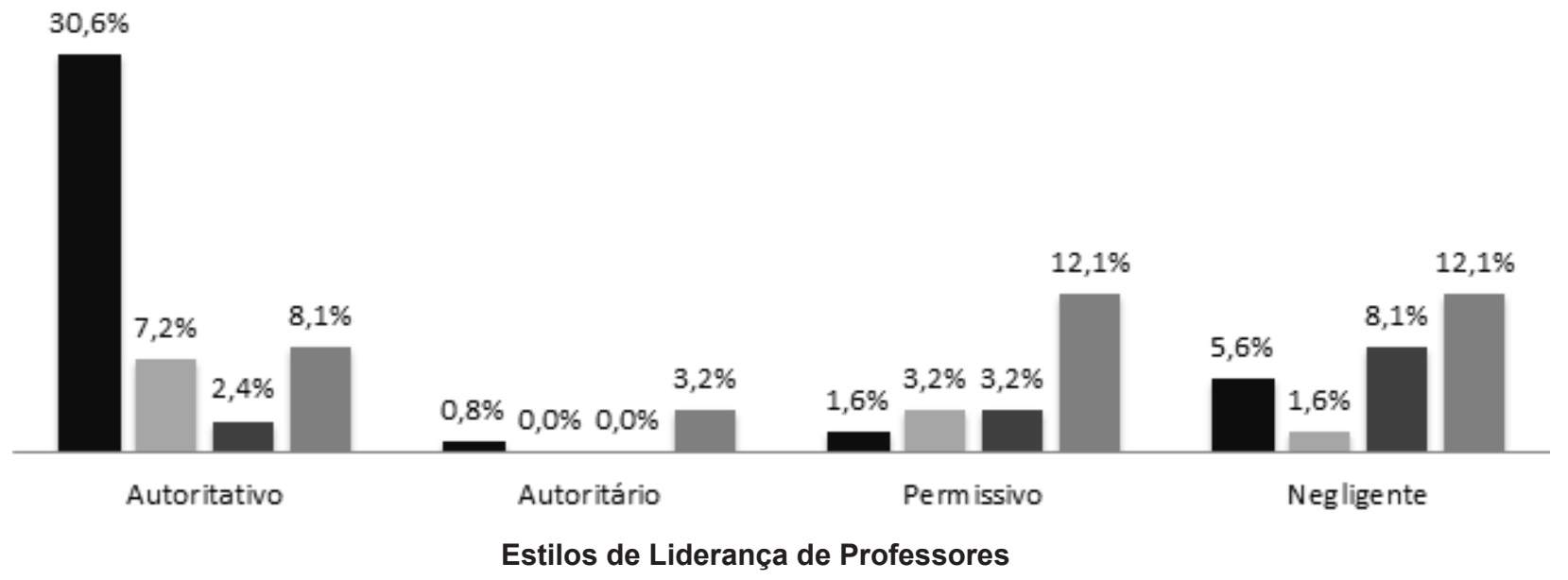

Figura 3. Frequência de cada classificação dos Estilos de Liderança de Professores a partir do cruzamento das Escalas de Responsividade e Exigência e de acordo com o tipo. 
Tabela 2. Correlação entre os itens da Escala de Autoconceito e Estilos de Liderança de Professores.

\begin{tabular}{|c|c|c|c|c|}
\hline & & Responsividade & Exigência & Controle Coercitivo \\
\hline \multirow[t]{2}{*}{ Pessoal } & Correlação de Pearson &,- 052 &,- 162 &,- 186 \\
\hline & Sig & ,569 & ,072 & ,039 \\
\hline \multirow[t]{2}{*}{ Escolar } & Correlação de Pearson & ,090 & ,122 & ,118 \\
\hline & Sig & ,320 & ,178 & ,191 \\
\hline \multirow[t]{2}{*}{ Familiar } & Correlação de Pearson & ,236 & , 168 &,- 151 \\
\hline & Sig &, 008 &, 062 & ,095 \\
\hline \multirow[t]{2}{*}{ Social } & Correlação de Pearson &,- 039 &,- 082 &,- 179 \\
\hline & Sig & ,668 & ,367 & ,046 \\
\hline \multirow[t]{2}{*}{ Geral } & Correlação de Pearson & 073 &, 005 &,- 145 \\
\hline & Sig & ,420 & ,952 & ,108 \\
\hline
\end{tabular}

conceito familiar. Por exemplo, no Inventário de Estilos de Liderança de Professores, na escala de responsividade o item "Minha professora pergunta o que os alunos fazem quando estão em casa" e na Escala de Autoconceito Familiar no item que diz "Digo a verdade quando estou com minha família".

O autoconceito familiar está ligado às relações e sentimentos que as crianças carregam das experiências familiares imprimindo-as em outros contextos como, por exemplo, na escala de autoconceito familiar podemos perceber o item "Quando ajudo em casa, faço tudo certo" e no IELP na escala de responsividade o item "Minha professora elogia quando os alunos acertam um exercício". Assim podemos perceber uma relação onde um comportamento é reforçado em um contexto (família), aumentando a probabilidade de se repetir e se generalizar para diferentes contextos, como na escola. A partir da perspectiva da análise do comportamento, considera-se que o aluno modifica o meio à medida que é modificado por ele. Dessa forma, o comportamento do aluno e da turma também influencia o estilo de liderança adotado pelo professor.

Outra correlação estatisticamente significativa é quanto ao controle coercitivo e o autoconceito pessoal, porém trata-se de uma correlação negativa, de modo que, quanto maior o controle coercitivo, menor é o autoconceito pessoal $\left(r=-0,19, r^{2}=3,6 \%\right)$. Talvez isso aconteça devido ao controle coercitivo estar ligado a um clima negativo em sala de aula, sendo que a criança passa grande parte de seu tempo na escola, e seu professor é um dos adultos de referência. Desse modo, a exposição a contingências aversivas pode influenciar o modo como a criança se vê de maneira pessoal. Se a criança vivencia situações em que seu comportamento é punido de forma inadequada, ou está constantemente ouvindo ameaças, ou ainda vivenciando climas aversivos, o modo como se percebe no mundo acaba sendo influenciado.
Uma terceira correlação, também negativa mostra que,quanto maior o controle coercitivo, menor é o autoconceito social $\left(r=-0,18 ; p=0,046 ; r^{2}=3,2 \%\right)$. O autoconceito social está relacionado aos ambientes e contextos em que a criança se encontra e como se percebe nas relações. A escola é um espaço de interações, um dos maiores espaços propícios para socialização. Sendo assim, o clima aversivo em sala de aula, constantes ameaças e falta de afetividade, podem influenciar a maneira com que a criança se vê dentro de cada ambiente.

O autoconceito se desenvolve ao longo de toda a vida e é formado a partir de várias experiências (Shavelson, Hubner, \& Stanton, 1996). Assim, se a criança está vivenciando o controle coercitivo, é possível que isso influencie seu autoconceito social, refletindo assim na socialização e nas suas relações. Por mais que contingências aversivas estejam presentes na sociedade e no sistema educacional como um todo, na relação professor-aluno elas ficam evidentes, pois aparecem no contato direto do dia-a-dia na sala de aula.

Essas correlações negativas mostram que o modo como o aluno se percebe pessoalmente e nas relações sociais podem sofrer influência da forma como os professores interagem com eles e os estilos de liderança que adotam, enfatizando que alunos de $4^{\circ}$ e $5^{\circ}$ anos passam grande parte do tempo na escola e geralmente possuem umúnico professor regente.

É importante destacar que, para as três correlações apontadas como estatisticamente significativas, os coeficientes de determinação $\left(r^{2}\right)$ foram consideravelmente baixos: $5,8 \%, 3,6 \%$ e $3,2 \%$, respectivamente. Ou seja, mesmo que a análise estatística tenha apontado como significativo, a porcentagem que um fator é determinado pelo outro é considerada baixa. Com isso, é importante apontar que tais resultados 
mostram uma relação estatística entre as variáveis, porém com baixo valor significativo para uma relação psicológica.

Outra questão levantada, é que não houve relação entre as escalas do IELP e o autoconceito escolar. Talvez isso se deva ao fato do instrumento IELP trazer questões referentes ao estilo de como o professor se comporta e, o instrumento que mede o autoconceito tratar de questões entre pares no ambiente da sala de aula. Ou ainda talvez, por serem utilizadas outras crianças como referencial de análise no instrumento de autoconceito, ou seja, analisando as situações com os pares, não abordando a relação professor-aluno em tal processo.

Também foi realizada uma análise para verificar se havia diferença estatística entre gênero e ano escolar com relação ao autoconceito. Os resultados apontaram para um valor significativo $(p<0,05)$ em que há um maior autoconceito escolar em meninos do que em meninas.

Wangby, Bergman, e Magnusson (1999) (conforme citado por Rocha, 2012) discutem em seu estudo a hipótese de as meninas tenderem a ser mais críticas consigo mesmas do que os meninos, em autoavaliações. Esse estudo mostra que o que fornece suporte para tal hipótese são as diferenças encontradas entre os sexos no que se refere às habilidades de comunicação, geralmente melhores desenvolvidas nas meninas, que podem gerar melhor capacidade de discriminação e autorrelato.

Já nas outras escalas não houve nenhuma diferença de acordo com o gênero. Quanto ao ano escolar os escores foram equilibrados, não havendo também nenhuma diferença significativa.

Em relação ao IELP foi realizada a mesma análise que mostrou que não há diferença entre meninos e meninas em relação aos escores obtidos nas escalas de responsividade, exigência e controle coercitivo. Porém, houve diferenças estatisticamente significativas quanto ao ano escolar $(p<0,05)$ sendo maior a utilização da responsividade e da exigência no $5^{\circ}$ ano e maior o uso do controle coercitivo no $4^{\circ}$ ano na amostra estudada.

\section{Considerações Finais}

O estudo apresentado teve como objetivo verificar a relação entre o autoconceito em crianças e os estilos de liderança de professores, além de apresentar resultados sobre o autoconceito e os estilos de liderança de professores na amostra estudada. A revisão da teoria e estudos relacionados à área destaca a relevância do presente estudo, uma vez que se observa claramente uma lacuna na literatura.

Os resultados apontaram uma correlação positiva entre a escala de responsividade e o autoconceito familiar, e duas correlações negativas, uma entre a dimensão controle coercitivo e o autoconceito pessoal e outra entre a dimensão controle coercitivo e o autoconceito social. Entretanto, é importante ressaltar que apesar de o estudo apontar três correlações estatisticamente significativas, o quanto um fator é determinado pelo outro é considerado baixo.
Outro resultado apresentado é com relação aos estilos de liderança de professores, em que a maioria dos alunos deu respostas que classificaram seus professores como pertencendo ao estilo autoritativo, considerado o melhor estilo de liderança. A somatória dos outros estilos demonstrou baixo uso de exigência, fato que deve ser levando em consideração já que a exigência (regras e limites) é essencial para um bom desenvolvimento das crianças, incluindo seu autoconceito. Além disso, todos os alunos apresentaram respostas que classificaram o controle coercitivo como tendência a baixo, ou seja, mesmo no estilo autoritativoum certo nível de controle coercitivo foi utilizado.

Quanto ao autoconceito, a maioria dos participantes $(49,3 \%)$ se classificou como possuindo um bom autoconceito geral, ou seja, se percebem como inteligentes, com boas relações e acreditam que possuem muitas capacidades.

Sabe-se que o autoconceito de crianças é construído a partir das relações estabelecidas nos ambientes em que se inserem. Nesse sentido, é importante considerar a história de cada criança esuas experiências, pois cada uma já passou por diversos ambientes e aprendizagens que também foram fatores de influência na construção do autoconceito.

A relação professor-aluno caminha no mesmo sentido, pois ao longo de sua trajetória escolar, os alunos passam por diversos professores e cada um tem seu repertório único, assim como sua metodologia de trabalho. Desse modo, deve-se considerar que os alunos no momento em que participam da pesquisa já haviam passado por alguns anos escolares e tiveram diferentes relações com diversos professores. Assim, conforme aponta Batista (2013), diversos fatores estão presentes e influenciam o comportamento de cada um dos envolvidos na relação professor-aluno, sendo que ambos apresentam um repertório prévio ao se encontrarem em sala de aula.

Destaca-se a importância de refletir sobre as interações que a criança estabelece nos diversos contextos em que está inserida, pois é a partir delas que ela vai adquirir um repertório comportamental adequado ou não e também obter uma visão de si mesma e dos outros.

\section{Referências}

Antunes, C. \& Fontaine, A. M. (2005). Percepção de apoio social na adolescência: Análise fatorial confirmatória da escala Social Support Appraisals. Paidéia, 15(32), 355-366.

Barbosa, A. J. G., Campos, R. A., \&Valentim, T. A. (2011). A diversidade em sala de aula e a relação professor-aluno. Estudos de Psicologia, 28(4), 453-461.

Batista, A. P. (2013). Construção e análise de parâmetros psicométricos do Inventário de Estilos de Liderança de Professores. Tese de Doutorado, Universidade Federal do Paraná, Curitiba-PR.

Batista, A. P. \& Weber, L. N. D. (2012). Estilos de liderança de professores: Aplicando o modelo de estilos parentais. Psicologia 
Escolar e Educacional, 16(2), 299-307.

Batista, A. P. \& Weber, L. N.D. (2015). Professores e Estilos de Liderança - Manual para Identificá-los e Modelo Teórico para Compreendê-los. Curitiba: Juruá.

Carneiro, G. R. S., Mattinelli, S. C., \& Sisto, F. F. (2003). Autoconceito e dificuldades de aprendizagem na escrita. Psicologia: Reflexão e Crítica, 16(3),427-434.

Cia, F. \& Barham, E. J. (2008). Estabelecendo relação entre autoconceito e desempenho acadêmico de crianças escolares. Psico, 39(1), 21-27.

Costa, P. C. G. (2002). Escala de autoconceito no trabalho: Construção e validação. Padéia, 18(1), 75-81.

Cozby, P. C. (2009). Métodos de pesquisa emciências do comportamento (1 ed.). São Paulo: Atlas.

Davis-Kean, P. E. \& Eccles, J. S. (2005). Influences and challenges to better parent-school collaborations. Em E. M. Patrikakou, R. P. Weissberg, S. Redding, H. J. Walberg (Orgs.), School-family partnerships for chidren's success. New York: Teacher College Press.

Gomide, P. (2006). Inventário de Estilos Parentais IEP: modelo teórico, manual de aplicação, apuração e interpretação. Rio de Janeiro: Vozes.

Hamre, B. K. \& Pianta, R. C. (2006).Student-teacher relationships. Em G. G. Bear \& K. M.Minke (Orgs.), Children's Needs II: development, prevention and intervention(pp. 49- 60). Bethesda, MD: National Association of School Psychologists.

Júnior, R. M. \& Cunha, C. A. (2007). Reconhecimento de palavras e de autoconceito num grupo de crianças. PSIC, 8(2), 215-226.

Maccoby, E. \& Martin, J. (1983). Socialization in the context of the family: Parent-child interaction. Em E. M. Hetherington (Org.), Socialization, personality, and social development (pp.1-101). New York: Wiley.

Mattos, A. R., Pérez, B. C., \& Castro, L. R. (2013).O cuidado na relação professor-aluno e sua potencialidade política. Estudos de Psicologia, 18(2), 369-377.
Pajares, F. (1996).Self-efficacy beliefs in academic settings. Review of Educational Research, 66(4), 543-578.

Pajares, F. \& Schunk, D. H. (2001).Self-Beliefs and school success: Self-Efficacy, self-concept, and school Achievement.

Palácios, J. \& Hidalgo, V. (1995). Desenvolvimento da personalidade nos anos pré-escolares. Porto Alegre: Artes médicas.

Ribeiro, M. L. (2010). A afetividade na relação educativa. Estudos de Psicologia, 27(3), 403-412.

Rocha, G. V. M., Ingberman, Y. K., \&Breus, B. (2011). Análise da relação entre práticas parentais e o autoconceito de pré-escolares. Revista Brasileira de Terapia Comportamental e Cognitiva, 8(1),87-106.

Rocha, M. M. (2012). Evidências de validade do "Inventário de Autoavaliação para Adolescentes" (YSR/ 2011) para a população brasileira. Tese de Doutorado, Universidade de São Paulo, São Paulo-SP.

Serra, A. V. (1988). O auto-conceito. Análise Psicológica, 2(6), 101110.

Shavelson, R. J., Hubner, J. J., Stanton, G. C. (1976). Self-concept: Validation of Construct Interpretations. Review of Educational Research, 46(3),407-441.

Sidman, M. (1995).Coerção e suas implicações. (M. A. Andery \& Sério, T. M. Trads.) São Paulo: Editorial Psy. (Trabalho original publicado em 1989).

Sisto, F. F. \& Martinelli, S. C. (2004). Escala de Autoconceitolnfanto Juvenil (EAC-IJ). São Paulo: Editora Vetor.

Souza, L. F. N. I. \& Brito, M. R. F. (2008). Crenças de auto-eficácia, autoconceito e desempenho em matemática. Estudos de Psicologia, 25(2), 193-201.

Weber, L. N. D., Prado, P. M., Viezzer, A. P. \& Brandenburg, O. J. (2004). Identificação de Estilos Parentais: O Ponto de Vista dos Pais e dos Filhos. Psicologia: Reflexão e Crítica, 17(3),323-331.

Review of Educational Research, 66 (4), 543-578 


\section{Sobre as autoras}

Jéssica Michelis Lemos (jessica_smn@hotmail.com)

Acadêmica de Psicologia.Universidade Estadual do Centro-Oeste.

Ana Priscila Batista (anapribatista@yahoo.com.br)

Universidade Estadual do Centro-Oeste. Graduada em Psicologia pela Universidade Estadual de Londrina - UEL, possui especialização em Terapia Comportamental e Cognitiva: teoria e aplicação pela Universidade de São Paulo - USP, mestrado em Psicologia Experimental pela Universidade de São Paulo - USP e doutorado em Educação pela Universidade Federal do Paraná - UFPR. É professora efetiva do Departamento de Psicologia da Universidade Estadual do Centro-Oeste - UNICENTRO, campus de Irati, PR. Coordena o Laboratório de Estudos sobre Infância e Adolescência (LEIA) na UNICENTRO. 